ARTICLE

DOI: $10.1038 / \mathrm{s} 41467-017-00154-x$

\title{
A three enzyme system to generate the Strychnos alkaloid scaffold from a central biosynthetic intermediate
}

Evangelos C. Tatsis (1) ${ }^{1}$, Inês Carqueijeiro (1) 2, Thomas Dugé de Bernonville (1) 2, Jakob Franke ${ }^{1}$ Thu-Thuy T. Dang ${ }^{1}$, Audrey Oudin², Arnaud Lanoue ${ }^{2}$, Florent Lafontaine ${ }^{2}$, Anna K. Stavrinides (1) ${ }^{1}$, Marc Clastre ${ }^{2}$, Vincent Courdavault (i) ${ }^{2} \&$ Sarah E. O'Connor (iD ${ }^{1}$

Monoterpene indole alkaloids comprise a diverse family of over 2000 plant-produced natural products. This pathway provides an outstanding example of how nature creates chemical diversity from a single precursor, in this case from the intermediate strictosidine. The enzymes that elicit these seemingly disparate products from strictosidine have hitherto been elusive. Here we show that the concerted action of two enzymes commonly involved in natural product metabolism - an alcohol dehydrogenase and a cytochrome P450-produces unexpected rearrangements in strictosidine when assayed simultaneously. The tetrahydro- $\beta$ carboline of strictosidine aglycone is converted into akuammicine, a Strychnos alkaloid, an elusive biosynthetic transformation that has been investigated for decades. Importantly, akuammicine arises from deformylation of preakuammicine, which is the central biosynthetic precursor for the anti-cancer agents vinblastine and vincristine, as well as other biologically active compounds. This discovery of how these enzymes can function in combination opens a gateway into a rich family of natural products.

\footnotetext{
${ }^{1}$ John Innes Centre, Department of Biological Chemistry, Norwich Research Park, Norwich NR4 7UH, UK. ${ }^{2}$ Université François-Rabelais de Tours, EA2106 Biomolécules et Biotechnologies Végétales, Parc de Grandmont 37200 Tours, France. Evangelos C. Tatsis and Inês Carqueijeiro contributed equally to this work. Correspondence and requests for materials should be addressed to V.C. (email: vincent.courdavault@univ-tours.fr) or to S.E.O. (email: sarah.oconnor@jic.ac.uk)
} 
$\mathrm{T}$ he medicinal plant Catharanthus roseus synthesizes a variety of biologically active monoterpene indole alkaloids, most notably the anti-cancer agents vinblastine and vincristine. Vinblastine and vincristine, along with many other monoterpene indole alkaloids, are derived from the biosynthetic intermediate, preakuammicine, as evidenced by extensive feeding studies and isolation of biosynthetic intermediates from plant material $^{1,}{ }^{2}$. However, discovery of the enzymes that are responsible for biosynthesis of the preakuammicine skeleton has proven elusive.

Nearly all monoterpene indole alkaloid pathways begin with deglycosylation of strictosidine by a dedicated glucosidase, strictosidine glucosidase $(\mathrm{SGD})^{3}$. Strictosidine aglycone, which can exist in numerous isomers such as 4,21-dehydrogeissoschizine, is then enzymatically transformed into the various monoterpene indole alkaloid skeletons. However, the enzymes responsible for the synthesis of preakuammicine, or any preakuammicinederived product from strictosidine aglycone remain unknown. While the enzymatic reactions remain cryptic, extensive isolation of reaction intermediates as well as model chemical studies suggest a sequence of reactions: 4,21-dehydrogeissoschizine (strictosidine aglycone isomer) is reduced to geissoschizine, which is followed by oxidative rearrangement and reduction to preakuammicine ${ }^{4-10}$. Preakuammicine can non-enzymatically deformylate to produce the alkaloid akuammicine ${ }^{8,}{ }^{10-12}$ or serve as a precursor for additional alkaloid scaffolds ${ }^{8}$.

Here we use a transcriptomic database for the medicinal plant Catharanthus roseus to identify two enzymes, an alcohol dehydrogenase (GS) and a cytochrome P450 (GO), that act in tandem on 4,21-dehydrogeissoschizine (strictosidine aglycone) to yield akuammicine, a Strychnos alkaloid. These enzymes are characterized by both in vitro and in planta silencing approaches. Akuammicine is known to arise from deformylation of preakuammicine $^{8}, 10-12$, which is the central biosynthetic precursor for the anti-cancer agents vinblastine and vincristine, as well as hundreds of other biologically active compounds. Therefore, these enzymes open a gateway into a rich family of natural products, and will facilitate metabolic engineering efforts to make high-value monoterpene indole alkaloids.

\section{Results}

Identification of gene candidates. To identify genes responsible for generating Strychnos scaffolds such as preakuammicine and akuammicine (Fig. 1a), we mined a transcriptomic database of C. roseus tissues ${ }^{13}, 14$, which also included data from plants with increased alkaloid levels due to folivory ${ }^{15}$. Gene candidates identified were initially screened in $C$. roseus by virus-induced gene silencing (VIGS), a transient silencing system in which qualitative perturbations in the metabolic profile between silenced and control tissue provide clues to the metabolic function of the gene of interest. Transformation into preakuammicine requires both reduction and oxidation steps (Fig. 1b, Supplementary Fig. 1) 1-10 $^{\text {. }}$ Therefore, we focused on alcohol dehydrogenases (reductase) and cytochromes P450 (oxidase); alcohol dehydrogenases have been implicated in other monoterpene indole alkaloid biosynthetic steps $^{16-18}$, and cytochromes P450 are well known to play important roles in oxidative transformations in plant metabolism ${ }^{16,19}$

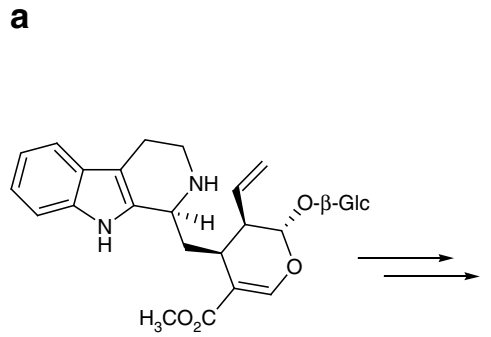

Strictosidine

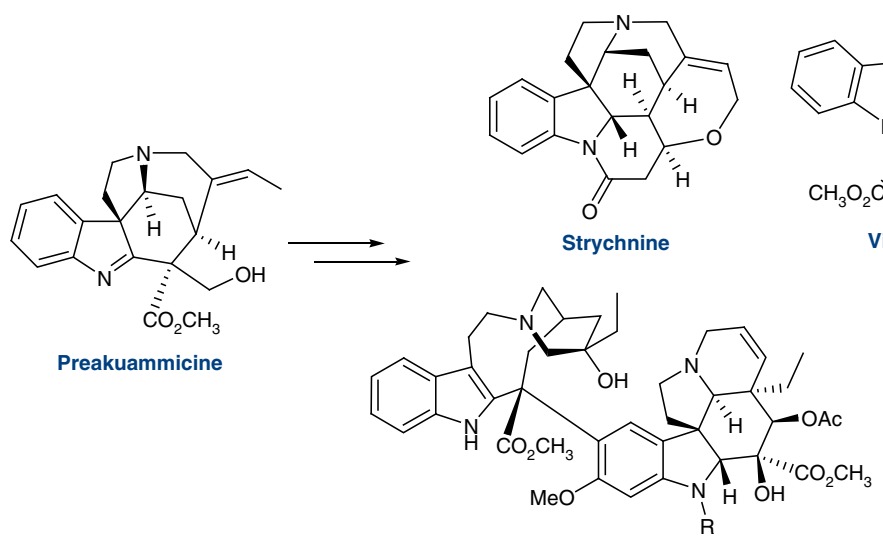

R: $\mathrm{CH}_{3}$ vinblastine R: CHO vincristine<smiles>CC[C@]12CCCN3CCc4c(n(c5ccccc45)[C@](O)(C(C)=O)C1)[C@]32C</smiles>

Vincamine

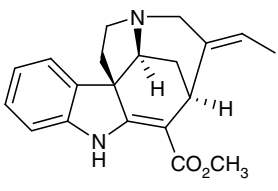

Akuammicine

b

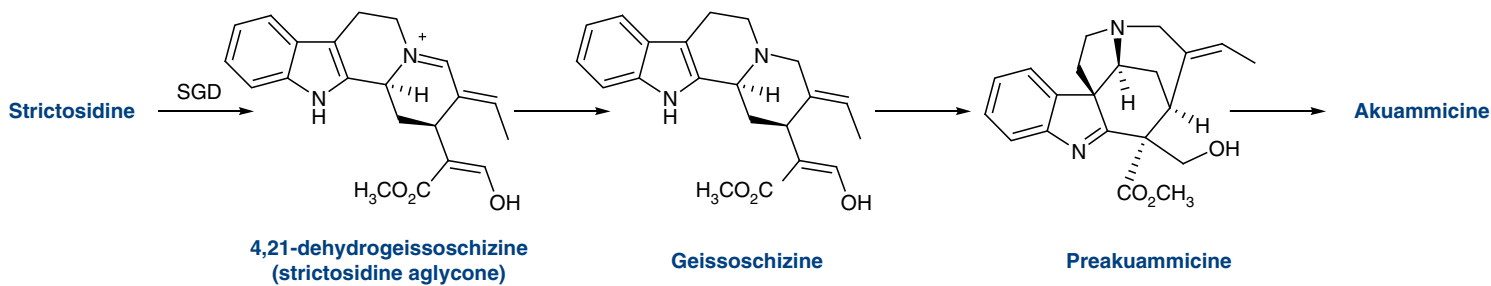

Fig. 1 Monoterpene indole alkaloid biosynthesis. a All ca. 2000 monoterpene indole alkaloids are derived from strictosidine, which is converted to preakuammicine through an unknown series of enzymatic reactions. Preakuammicine is hypothesized to be the precursor for many structurally divergent alkaloids. b A schematic overview of the proposed pathway that generates the Strychnos alkaloid akuammicine. Strictosidine is deglycosylated by the known enzyme, strictosidine glucosidase (SGD). An isomer of strictosidine aglycone, 4,21-dehydrogeissoschizine, can be reduced to form geissoschizine, which feeding studies suggest rearranges to form preakuammicine. Preakuammicine can deformylate to form the Strychnos alkaloid akuammicine, and is also hypothesized to be the precursor for many downstream alkaloids. See Supplementary Fig. 1 for a more detailed picture of monoterpene indole alkaloid biosynthesis 
In planta and in vitro assay of enzyme candidates. Prioritization of genes through Pearson's correlation coefficient (PCC) determination revealed a limited number of candidates displaying correlation with SGD (549 with PCC > 0.6), with only two candidates predicted to encode cytochromes P450 (Supplementary Data 1). One was secologanin synthase, which is involved in upstream monoterpene indole alkaloid biosynthesis ${ }^{20,21}$ and the second was CYP71D1V1, which was previously deposited as JN613015 in a previous report, though not functionally characterized $^{22}$. Silencing CYP71D1V1 led to a statistically significant decreases in the production of the alkaloids catharanthine, vindoline and vindorosine (Supplementary Fig. 2a), iboga and aspidosperma type alkaloids that are derived from preakuammicine (Supplementary Fig. 1) ${ }^{23}$.

All literature reports suggest geissoschizine $(m / z \quad 353)$, a reduction product of the 4,21-dehydrogeissoschizine isomer of strictosidine aglycone, is the precursor for preakuammicine (Fig. 1b $)^{4}, 5,10$. As part of an effort to characterize alcohol dehydrogenases of $C$. roseus, we noted that silencing of one medium chain alcohol dehydrogenase gene (named GS1 for

a

Strictosidine 4,21-dehydrogeissoschizine

(E)-geissoschizine

Preakuammicine<smiles>C=C[C@@H]1[C@H](OC(C)(C)C)OC=C(C(=O)OC)[C@H]1CC1NCCc2c1[nH]c1ccccc21</smiles><smiles>C/C=C1/C=NC23CC(/C(=C/O)C(C)=O)C1C=CN2CCc1c3[nH]c2ccccc12</smiles>

GS<smiles>C/[I+]=C(/C(C)=O)[C@H]1CC2c3[nH]c4ccccc4c3CCN2C/C1=C/[O-]</smiles>
Go<smiles>C/C=C1\CN2CCc3c([nH]c4ccccc34)[C@@H]2CC1C(CO)C(C)=O</smiles>

(16R)-Z-isositsirikine<smiles>C/C=C1/CN2CCc3c([nH]c4ccccc34)C2CC(C(C)(CO)C(C)=O)C1CCC</smiles>

(16R)-E-isositsirikine
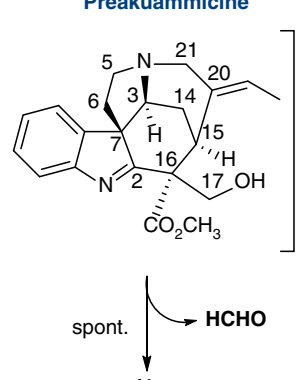

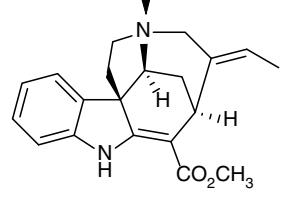

Akuammicine b

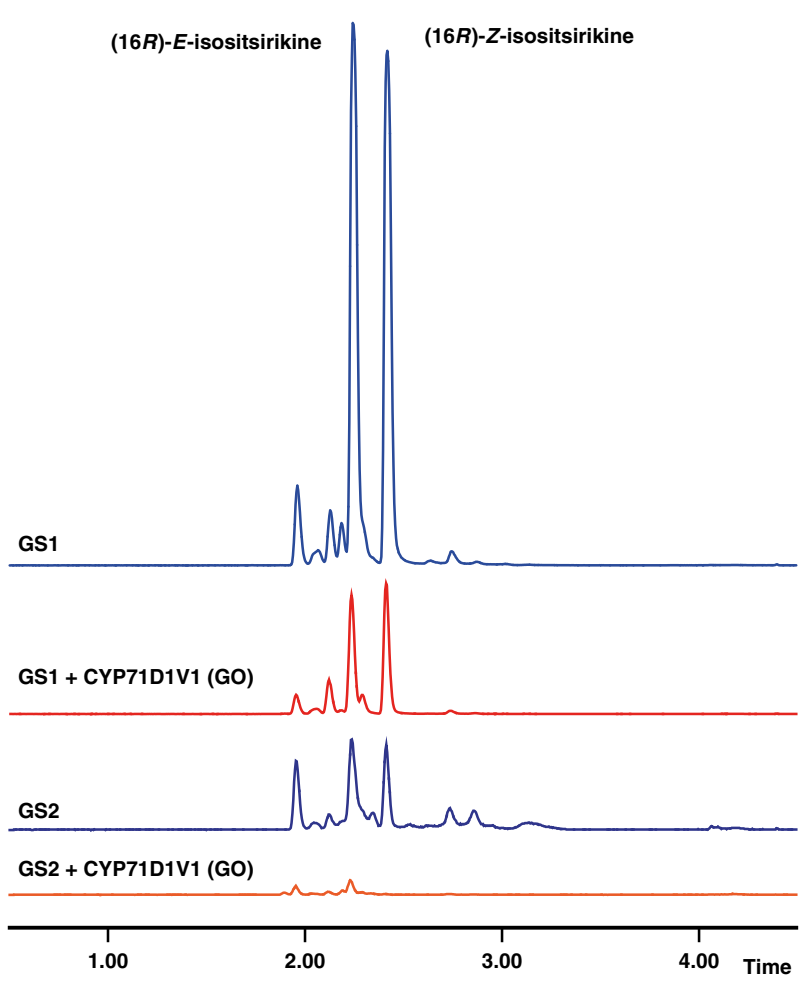

C

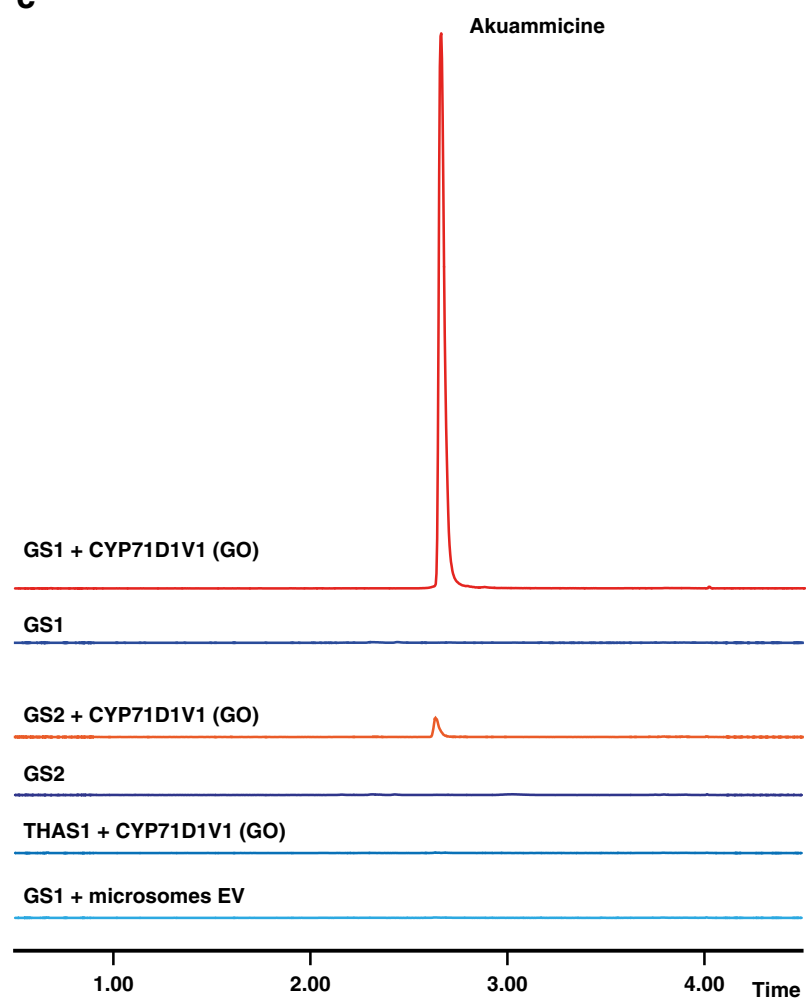

Fig. 2 Enzymatic activity of GS1 and GS2 and GO (CYP71D1V1). a Reaction of strictosidine with SGD, GS and GO. b Multiple reaction monitoring (MRM) on a LCMS showing compounds at $\mathrm{m} / \mathrm{z} 355$ in enzymatic assays of GS1/2 and GO. Isolation and NMR characterization of the two major compounds indicated that they are (16R)-E-isositsirikine and (16R)-Z-isositsirikine (Supplementary Figs 5-16). c MRM ( $\mathrm{m} / z$ 323) of an akuammicine standard compared with enzymatic products of GS1/2 and GO. THAS1 is a medium chain alcohol dehydrogenase involved in the heteroyohimbine monoterpene indole alkaloid pathway (Supplementary Fig. 1). EV empty vector 

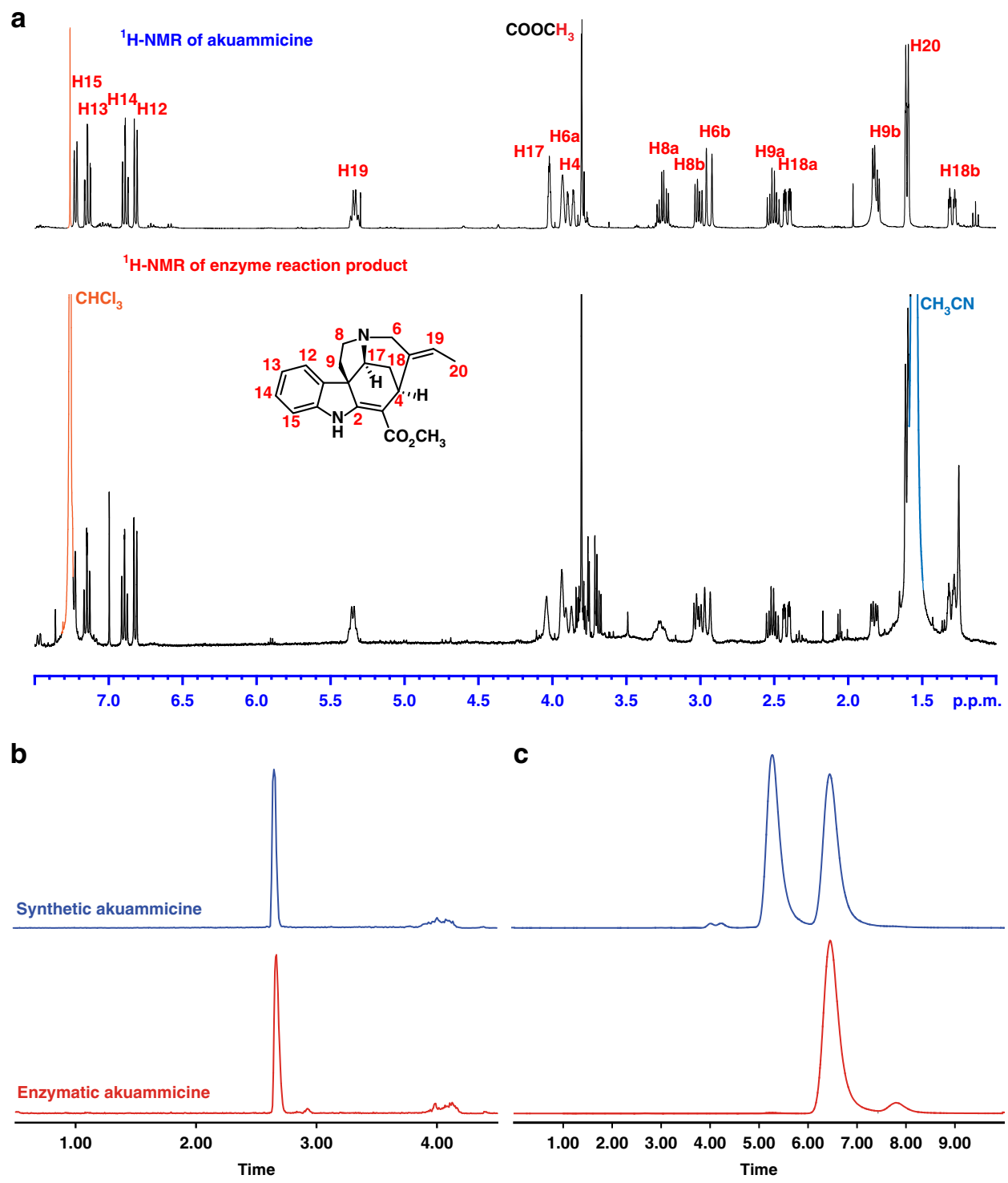

Fig. 3 Characterization of the GS1/GO product, akuammicine. a. ${ }^{1} \mathrm{H}$ NMR of enzymatically produced akuammicine compared to a synthetic standard (see also Supplementary Figs 19-23). b. LC-MS chromatograms with a standard reverse phase column comparing synthetic akuammicine with the enzymatic product. c Chiral LC-MS chromatograms comparing the racemic synthetic standard with the enzymatic product

geissoschizine synthase), led to only minor changes in alkaloid profiles (Supplementary Fig. 3). Since VIGS phenotypes can be attenuated by factors such as enzyme redundancy or molecule transport, we nevertheless assayed the protein in vitro. When the protein encoded by this gene (initially reported but not functionally characterized during a search for strictosidine biosynthetic genes as KF302079.1 ${ }^{16}$ ) was heterologously expressed in E. coli (Supplementary Fig. 4) and assayed with strictosidine in the presence of SGD, the enzymatic reaction yielded a mixture of products, primarily consisting of two compounds $(m / z$ 355) (Fig. 2b). Isolation and NMR characterization showed that the two major products of this enzymatic reaction are (16 R)-E-isositsirikine (high-resolution $\mathrm{MS}[\mathrm{M}+\mathrm{H}]^{+}$ 355.2020 ; isolated in ca. $38 \%$ yield) and (16R)- $Z$-isositsirikine (high-resolution MS $[\mathrm{M}+\mathrm{H}]^{+} 355.2014$; isolated in $c a .7 \%$ yield) (Fig. 1a, Supplementary Figs 5 and 16) 24,25 . In addition, a homolog of GS1 (GS2, KF302078.1 ${ }^{16}$ ) was also identified and tested. This enzyme was purified in lower yields from $E$. coli (Supplementary Fig. 4) but produced the same products as GS1 in decreased quantity. While the formation of isositsirikine initially led us to dismiss GS1/GS2 as candidates for geissoschizine synthase, we noted that in CYP71D1V1 silencing experiments, a compound with the same $\mathrm{m} / z$ and retention time as (16R)-Eisositsirikine accumulated (Supplementary Fig. 2b, Supplementary Fig. 17). This provided an important clue that the enzymatic reactions of GS1 and CYP71D1V1 are coupled. We hypothesized that GS1/GS2 initially produces geissoschizine, which is captured and then oxidized to preakuammicine when the correct downstream oxidase is present. However, in the absence of a downstream enzyme, geissoschizine could be over-reduced by GS1/GS2 to the more stable (16R)-Z, E-isositsirikine products. Notably, the $E$-isositsirikine isomer, which is the major enzymatic product and also the isomer that accumulates in CYP71D1V1silenced tissues, has the same C19-20 bond geometry as geissoschizine ${ }^{9}$.

To test this hypothesis, CYP71D1V1, a microsomal enzyme, was heterologously expressed in a yeast strain harboring a cytochrome P450 reductase, and the microsomes were harvested. When SGD, CYP71D1V1 and GS1 were incubated together with strictosidine, using selected ion monitoring at $\mathrm{m} / z 355$ we noted 
a

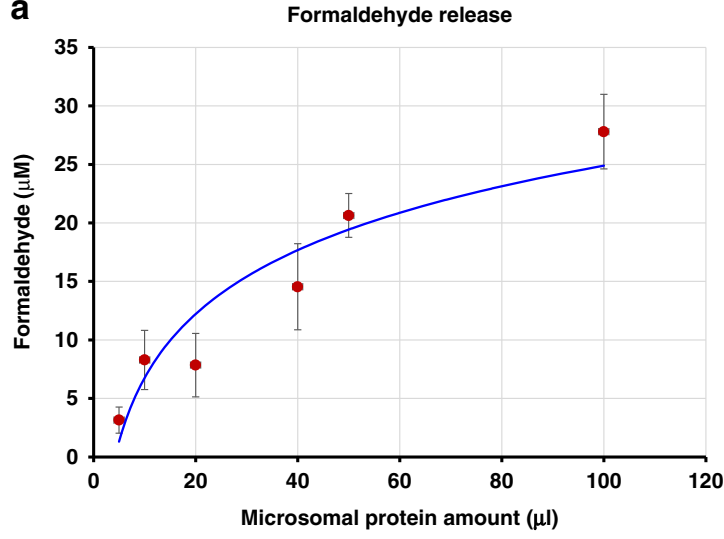

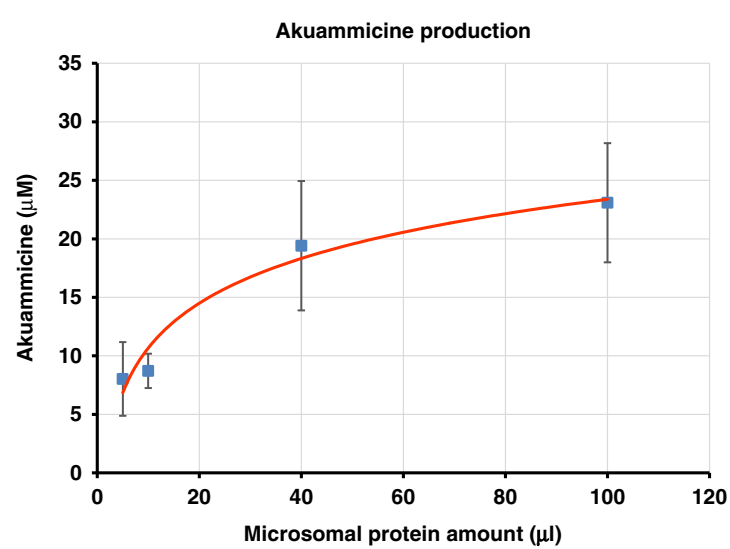

b

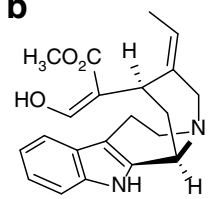

Geissoschizine

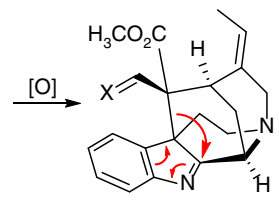

Rhazimal $\mathrm{X}=\mathrm{O}$

$\left[\mathrm{H}^{-}\right]$

Rhazimol $\mathrm{X}=\mathrm{OH}, \mathrm{H}$

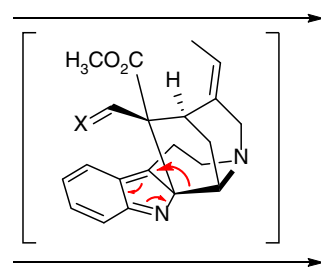

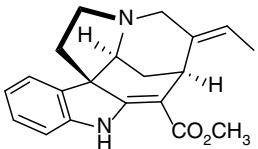

16-R-dehydro-

preakuammicine $\mathrm{X}=\mathrm{O}$

$\left[\mathrm{H}^{-}\right]$

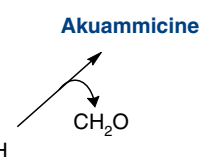

16R-preakuammicine $\mathrm{X}=\mathrm{OH}, \mathrm{H}$

Fig. 4 Deformylation in the formation of akuammicine. a Deformylation as measured with Nash reagent correlates with akuammicine production as measured by mass spectrometry (see also Supplementary Figs 27-29). b Possible mechanistic scenario for rearrangement of geissoschizine to the preakuammicine skeleton as suggested by Benayad et al. ${ }^{10}$. Error bars represent standard error of three replicates

the same product profile observed with GS1 lacking CYP71D1V1, but the amounts of the products appeared to be decreased (Fig. 2b). However, no new product corresponding to preakuammicine $(\mathrm{m} / \mathrm{z} 353)$, dehydropreakuammicine $(\mathrm{m} / \mathrm{z} 351)$ or any potential isomers of these compounds, was observed. Notably, preakuammicine can non-enzymatically deformylate to yield akuammicine $(m / z 323)^{8}$, and is generally regarded as the direct precursor to akuammicine ${ }^{10}$. Careful analysis of the mass spectra of the GS1 (or GS2) and CYP71D1V1 reaction revealed a compound with $m / z 323$ (high-resolution MS $[\mathrm{M}+\mathrm{H}]^{+} 323.1760$ ) (Fig. 2c). This enzymatically produced compound was isolated (ca. $12.5 \%$ yield), characterized by NMR (Supplementary Figs 18-23) and shown to be identical to a synthetic standard of akuammicine (Fig. 3a, b) ${ }^{26}$. Moreover, the enzymatic akuammicine product was observed to be enantiopure on a chiral column (Fig. 3c). Formation of akuammicine was absolutely dependent on the presence of CYP71D1V1-expressing microsomes (Fig. 2c). On this basis, CYP71D1V1 was named geissoschizine oxidase (GO). In addition, replacement of GS1 or GS2 with another medium chain alcohol dehydrogenase, THAS1, which is involved in an unrelated branch (heteroyohimbine) of monoterpene indole alkaloid biosynthesis ${ }^{18}$ failed to yield akuammicine (Fig. $2 \mathrm{c}$ ).

GS1 and GO must be added to strictosidine aglycone simultaneously for akuammicine to be produced (Supplementary Fig. 24), suggesting that the GS1 reaction product that acts as the substrate for GO (i.e., geissoschizine) is rapidly metabolized. A small amount of compound with a mass consistent with geissoschizine $(\mathrm{m} / \mathrm{z} 353)$ was observed in the GS1 enzymatic reaction, but this compound could not be isolated in sufficient quantities for characterization (Supplementary Fig. 25). In vivo, both GS1 and GO transcripts are enriched in the epidermis relative to whole leaf, consistent with the epidermal location of other monoterpene indole alkaloid enzymes such as strictosidine synthase and SGD (Supplementary Fig. 26a) ${ }^{27}$. At the subcellular level, YFP-labeling of GO and GS1 suggests that GS1 has a nucleocytosolic location while GO is anchored to the ER, potentially facilitating GS1-reaction product uptake (Supplementary Fig. 26b). Collectively, these data suggest that GS1 and GO are located in close proximity in planta, consistent with a coupled role in vivo.

Mechanism of akuammicine formation. The mechanistic basis of the rearrangement of the tetrahydro- $\beta$-carboline scaffold of strictosidine to the Strychnos scaffold remains to established, but the literature provides some clues. Akuammicine can be generated from preakuammicine by non-enzymatic deformylation (Fig. $4 a)^{8}, 10$. Production of formaldehyde during the enzyme assay in approximately equimolar concentration as akuammicine provides indirect support for the formation of preakuammicine (Fig. 4a, Supplementary Figs 27-29). Geissoschizine, which has been shown by feeding studies to be the akuammicine precursor, is proposed to undergo oxidative reaction to form rhazimal. Recent elegant model chemistry suggests that rhazimal, or its reduced counterpart, rhazimol, can rearrange to dehydropreakuammicine or preakuammicine, respectively (Fig. $4 \mathrm{~b})^{10}$. Therefore, we hypothesize that a reductase generates geissoschizine from strictosidine aglycone (4,21-dehydrogeissoschizine isomer). Then, an oxidase transforms geissoschizine to rhazimal, which then rearranges to dehydropreakuammicine, which is then reduced to preakuammicine. Alternatively, rhazimal could be reduced to rhazimol, which rearranges directly to preakuammicine. However, monoterpene indole alkaloid biosynthesis in strychnine biosynthesis likely proceeds via dehydropreakuammicine $^{28}$. GS1/GS2 or an endogenous reductase present in the yeast microsomes could catalyze the reduction of rhazimal or dehydropreakuammicine. 


\section{Discussion}

All monoterpene indole alkaloids emerge from rearrangement of the same precursor, strictosidine ${ }^{1}$. A number of these alkaloids (e.g., vinblastine, strychnine, quinine, camptothecin) are used clinically ${ }^{1,2}$. The different mechanisms by which strictosidine rearranges to form these structurally diverse compounds have been studied extensively, though only enzymes that catalyze the simplest rearrangement have been reported to date ${ }^{17,18}$. One of the most important-and cryptic-rearrangements of strictosidine is its conversion into the biosynthetic intermediate preakuammicine, the precursor for the Strychnos alkaloids, which include neurotoxic agents such as strychnine, as well as the precursor for the aspidosperma and iboga alkaloids that include the anti-cancer agent vinblastine (Supplementary Fig. 1) ${ }^{1}$.

While recent synthetic efforts have demonstrated how the monoterpene indole alkaloids can be chemically synthesized from a common scaffold ${ }^{29}$, the enzymes that control rearrangement and chemical diversification of the central intermediate found in the biological system have largely remained cryptic. In this manuscript, we report the discovery of two enzymes, an alcohol dehydrogenase (GS) and a cytochrome P450 (GO), that convert strictosidine aglycone into the Strychnos alkaloid akuammicine, a $\kappa$-opioid receptor agonist ${ }^{11,12}$. Together, these three enzymes catalyze a series of tandem reactions that lead to the remarkable rearrangement of the tetrahydro- $\beta$-carboline strictosidine substrate into the Strychnos-type scaffold. VIGS data are supportive of a role in planta, though the weak phenotype of GS suggests that there may be redundancy with this enzyme.

Though extensive model chemistry reported in the literature has provided some mechanistic insights into this enzymatic transformation, aspects of the mechanism of this transformation remain cryptic. Regardless, the discovery of GO and GS1 provides considerable insight into the biocatalytic processes involved in the diversification of monoterpene indole alkaloid structures, and provides an important step forward for the complete elucidation of metabolic pathways leading to biologically active molecules in this family, such as vinblastine. Importantly, this work has highlighted that to unlock the chemical diversity of certain plant pathways, the instability of the reaction intermediates requires that enzymes must be tested in combination. Therefore, methods to rapidly screen enzyme combinations are likely to be required to identify the genes of many plant natural product pathways. In summary, the discovery of these enzymes demonstrate the extraordinary chemistry that takes place in plants, and this discovery will enable metabolic engineering efforts to overproduce these high-value molecules.

\section{Methods}

Correlation analysis for selection of P450 candidates. An expression matrix was generated using the CDF97 consensus transcriptome ${ }^{30}$ after pseudo-mapping reads from paired-end sequencing runs available from EBI ENA (ERR1512369, ERR1512370, ERR1512371, ERR1512372, ERR1512373, ERR1512374,

ERR1512375, ERR1512376, ERR1512377, SRR1144633, SRR1144634, SRR1271857, SRR1271858, SRR1271859, SRR342017, SRR342019, SRR342022, SRR342023, SRR646572, SRR646596, SRR646604, SRR648705, SRR648707, SRR924147, and SRR924148). Quantification was achieved with Salmon v0.7.2 in the variational bayesian optimized (--vbo) quasi-mapping mode with bias correction (--biasCorrect) ${ }^{31}$. Correlations were calculated with $\mathrm{R}$ ( $\mathrm{R}$ Development Core Team, 2015).

Cloning. The entire coding sequence of GS1 was amplified from Catharanthus roseus cDNA using primers 5'-AAGTTCTGTTTCAGGGCCCGGCTGGAGAAA CAACAAAACTAG-3' and 5'-ATGGTCTAGAAAGCTTTATTCCTCAAATTTC AATGTATTT- $3^{\prime}$ and cloned into pOPIN-F expression vector ( $\mathrm{N}$ terminus $6 \mathrm{x}$ HisTag) using In-Fusion cloning while GS2 was cloned into the same expression vector using the following synthesized DNA fragment with GeneArt String method (ThermoFischer, USA) 5'-AAGTTCTGTTTCAGGGCCCGGCTGGAGAAACAA CAAAACTAGACCTTTCAGTGAAGGCCATCGGATGGGGTGCTGCAGATGC ATCTGGCGTTCTTCAGCCCATTAGGTTCTATAGAAGAGCCCCTGGTGA ACGGGATGTGAAGATTAGAGTTTTGTACTGTGGTGTGTGCAATTTCGAT
ATGGAAATGGTCAGAAACAAGTGGGGTTTCACTAGATACCCTTATGTTT TTGGACATGAGACCGCCGGTGAGGTGGTAGAAGTTGGGAAGAAAGTAG AGAAATTCAAGGTTGGAGATAAGGTGGGCGTGGGATGTATGGTCGGAT CTTGTGGCAAATGTTTCCATTGTCAAAACGAAATGGAGAATTACTGCC CGGAGCCTAATTTGGCTGATGGATCTACTTACCGTGAAGAAGGAGAAC GTTCCTATGGAGGTTGTTCAAATGTCATGGTTGTTGATGAAAAATTCG TCCTTAGATGGCCCGAAAATTTGCCTCAAGATAAAGGAGTTCCTCTCCT CTGTGCTGGGGTTGTTGTTTATAGCCCCATGAAATATATGGGATTTGAT AAGCCAGGAAAGCATATTGGGGTTTTTGGGTTGGGTGGTCTTGGTTCCA TTGCTGTTAAGTTTATTAAAGCTTTTGGTGGTAAGGCTACTGTTATTAGT ACATCAAGGCGTAAAGAGAAGGAAGCCATTGAAGAGCATGGAGCTGA TGCTTTTGTTGTCAACACTGACTCTGAACAATTGAAGGCTCTGGAAGGT ACTATGGATGGTGTTGTGGACACCACCCCAGGTGGCCGCACTCCTAT GCCACTTATGCTCAATTTGGTTAAGTTTGACGGCGCCGTTATACTCGTC GGTGCACCGGAGACGCTATTTGAGCTCCCGTTGGAGCCTATGGGAAGGA AAAAGATAATCGGAAGCTCCACTGGAGGTCTCAAAGAGTATCAAGAAGT GCTTGATATTGCAGCCAAACACAACATTGTATGTGATACTGAGGTTAT TGGGATTGATTATCTCAGCACTGCTATGGAACGCATCAAGAATTTGGAT GTCAAGTACCGATTCGCGATCGACATTGGGAATACATTGAAATTTGAGG AATAAAGCTTTCTAGACCAT.-3'

The CYP71D1V1 coding sequence was amplified using primers $5^{\prime}$-CTGAGAA CTAGTATGGAGTTTTCTTTCTCCTCACCAG- ${ }^{\prime}$ and $5^{\prime}$-CTGAGAACTAGTCT AATCGTTAACAAGATGAGGAACCAATT- $3^{\prime}$ and cloned into pESC-HIS expression vector (Agilent Technologies) prior to protein expression in yeast.

Protein expression. GS1 and GS2 enzymes were expressed in SoluBL21 (DE3) E. coli cells (Genlantis) grown in LB medium. A starter culture was grown overnight at $37^{\circ} \mathrm{C}$ in $100 \mathrm{~mL}$ of $2 \mathrm{xYT}$ media supplemented with carbenicillin $(100 \mu \mathrm{g} / \mathrm{ml})$. A 1:100 dilution in fresh $2 x Y T(2 \times 11)$ media supplemented with antibiotics was prepared and allowed to grow at $37^{\circ} \mathrm{C}$ to an $\mathrm{OD}_{600}$ of 0.8 . Protein production was induced by addition of $0.5 \mathrm{mM}$ IPTG and the cultures were shaken at $18^{\circ} \mathrm{C}$ for $16 \mathrm{~h}$ Cells were collected by centrifugation, lysed by sonication in Buffer A (50 mM Tris$\mathrm{HCl} \mathrm{pH} 8,50 \mathrm{mM}$ glycine, $500 \mathrm{mM} \mathrm{NaCl}, 5 \%$ v/v glycerol, $20 \mathrm{mM}$ imidazole) supplemented with EDTA-free protease inhibitor (Roche Diagnostics Ltd.) and $0.2 \mathrm{mg} / \mathrm{ml}$ lysozyme.

Cells were lysed using sonication for $3 \mathrm{~min}$ on ice using $2 \mathrm{~s}$ pulses. All purification steps were performed at $4^{\circ} \mathrm{C}$ on an ÄKTAxpress purifier (GE Healthcare). His-tagged enzyme was purified using a HisTrap FF $5 \mathrm{ml}$ column (GE Healthcare) equilibrated with Buffer A. The sample was loaded at a flow rate of $4 \mathrm{ml} / \mathrm{min}$ and step-eluted with Buffer B (50 mM Tris- $\mathrm{HCl} \mathrm{pH} \mathrm{8,50} \mathrm{mM} \mathrm{glycine,}$ $500 \mathrm{mM} \mathrm{NaCl}, 5 \%$ glycerol, $500 \mathrm{mM}$ imidazole). Eluted protein was subjected to further purification on a Superdex Hiload 26/60 S75 gel filtration column (GE Healthcare) at a flow rate of $3.2 \mathrm{ml} / \mathrm{min}$ using Buffer C (20 mM Hepes pH 7.5, $150 \mathrm{mM} \mathrm{NaCl}$ ) and collected into $8 \mathrm{ml}$ fractions. After analysis by SDS-PAGE, those fractions containing no traces of other contaminating proteins were pooled and dialyzed in Buffer $\mathrm{C}(50 \mathrm{mM}$ phosphate $\mathrm{pH} 7.6,100 \mathrm{mM} \mathrm{NaCl})$ and concentrated. Protein concentration was measured at $280 \mathrm{~nm}$ with Nanodrop according to the manufacturer's software. Purified proteins were divided in $20 \mu \mathrm{l}$ aliquots, fast-frozen in liquid nitrogen and stored at $-20^{\circ} \mathrm{C}$.

CYP71D1V1 enzyme was expressed in the Saccharomyces cerevisiae WAT11 cells ${ }^{32}$ grown in synthetic complete without histidine medium (SC-His) plus $2 \%$ Glucose. A starter culture was grown for $48 \mathrm{~h}$ at $30{ }^{\circ} \mathrm{C}$ in $100 \mathrm{~mL}$ of SC-His media supplemented with $2 \%$ Glucose. A 1:100 dilution in fresh SC-His $(4 \times 1 \mathrm{l})$ media supplemented with $2 \%$ Glucose was prepared and allowed to grow at $30^{\circ} \mathrm{C}$ $24 \mathrm{~h}$. Yeast cells were collected by centrifugation and resuspended in SC-His $(4 \times 11)$ media and protein production was induced by addition of $2 \%$ galactose and the cultures were shaken at $30^{\circ} \mathrm{C}$ overnight. The following day $(20 \mathrm{~h}$ later $)$, cells were collected by centrifugation, lysed by French Disruption Cell Press (one shot at $25 \mathrm{kPSI}$ ) in Buffer D (50 mM Tris, pH 7.4, $1 \mathrm{mM}$ EDTA, 0.6 M sorbitol). After centrifugation at $35,000 \times g$ for $10 \mathrm{~min}$ and precipitation of cell debris, the supernatant was centrifuged at $100,000 \times g$ for $1 \mathrm{~h}$. The pellet was resuspended in Buffer E (50 mM Tris, pH 7.4, 1 mM EDTA, $20 \%$ glycerol). In total, from 41 of yeast culture, a yield of $28 \mathrm{ml}$ of microsomal protein resulted. Purified microsomal protein was divided in $500 \mu \mathrm{l}$ aliquots, fast-frozen in liquid nitrogen and stored at $-80^{\circ} \mathrm{C}$

Enzyme assays. Purified GS1 or GS2 and purified SGD ${ }^{17}$ were used in all assays. CYP71D1V1 was used as a microsome preparation as described above. Strictosidine was purified by preparative reverse phase HPLC and quantified using ${ }^{1} \mathrm{H}$ NMR as previously described ${ }^{17}$. The strictosidine aglycone substrate was generated by deglycosylating strictosidine $(100$ or $300 \mu \mathrm{M})$ by the addition of purified SGD in the presence of $50 \mathrm{mM}$ phosphate buffer ( $\mathrm{pH} 7.0$ ) at $37^{\circ} \mathrm{C}$ for $15 \mathrm{~min}$. The reactions were started by the addition of GS1 or GS2 enzymes $(5 \mu \mathrm{M}), \mathrm{NADPH}$ $(5 \mathrm{mM})$ and microsomal protein containing GO (CYP71D1V1) $(25 \mu \mathrm{l})$ at $37^{\circ} \mathrm{C}$ in a total volume of $100 \mu \mathrm{l}$ with light shaking. Caffeine $(50 \mu \mathrm{M})$ was used as internal standard. All reactions were performed in quadruplicate. Aliquots of the reaction mixtures $(10 \mu \mathrm{l})$ were sampled $2,5,15,30,45$ and $60 \mathrm{~min}$ after addition of the GS and GO (CYP71D1V1) enzyme. The reactions were stopped by the addition of 10 $\mu \mathrm{l}$ of $100 \% \mathrm{MeOH}$. Samples were diluted further $1: 5$ in mobile phase $\left(\mathrm{H}_{2} \mathrm{O}+0.1 \%\right.$ 
formic acid) and centrifuged for $10 \mathrm{~min}$ at $4000 \times \mathrm{g}$ before UPLC-MS injection $(1 \mu \mathrm{l})$. The activity of enzymes was measured by UPLC-MS.

UPLC-MS chromatography was performed on a BEH Shield RP18 $(50 \times 2.1$ $\mathrm{mm} ; 1.7 \mu \mathrm{m}$ ) column (Waters). The solvents used were $\mathrm{H}_{2} \mathrm{O}+0.1 \%$ formic acid as Solvent $\mathrm{A} 1$ and $100 \%$ acetonitrile as Solvent B1, with a flow rate of $0.6 \mathrm{ml} / \mathrm{min}$. Injection volume was $1 \mu \mathrm{l}$. The gradient profile was $0 \mathrm{~min}, 5 \% \mathrm{~B} 1$; from 0 to 3.5 min, linear gradient to $35 \% \mathrm{~B} 1$; from $3.5 \mathrm{~min}$ to $3.75 \mathrm{~min}$, linear gradient to $100 \%$ $\mathrm{B} 1$; wash at $100 \% \mathrm{~B} 1$ for $1 \mathrm{~min}$; from $4.75 \mathrm{~min}$ to $6 \mathrm{~min}$, back to $5 \% \mathrm{~B} 1$ for $1 \mathrm{~min}$ to re-equilibrate the column.

Mass spectrometry detection was performed on a Waters Xevo TQ-S mass spectrometer (Milford, MA, USA) equipped with an electrospray (ESI) source. Capillary voltage was $2.5 \mathrm{kV}$ in positive mode; the source was kept at $150^{\circ} \mathrm{C}$; desolvation temperature was $500^{\circ} \mathrm{C}$; cone gas flow, $50 \mathrm{l} / \mathrm{h}$; and desolvation gas flow, $900 \mathrm{l} / \mathrm{h}$. Unit resolution was applied to each quadrupole.

Targeted methods for each compound were developed using either commercial standards (caffeine, ajmalicine, serpentine, catharanthine, vindoline, vindorosine, loganic acid, tetrahydroalstonine, and yohimbine were purchased from SigmaAldrich and tabersonine from Avachem Scientific) or enzymatically produced compounds isolated as described here or as previously reported (strictosidine ${ }^{17}$ and isositsirikine, this work). Akuammicine was synthesized and provided as a gift ${ }^{26}$. Flow injections of each individual compound were used to optimize the MRM conditions. This was done automatically using the Waters Intellistart software. A minimum dwell time of $25 \mathrm{~ms}$ was applied to each MRM transition. Four transitions were used to monitor the elution of tetrahydroalstonine and ajmalicine: $\mathrm{m} / \mathrm{z} 353.2>117.0$ (Cone 50, Collision 46), $\mathrm{m} / \mathrm{z} 353.2>144.0$ (Cone 50, Collision 26), $\mathrm{m} / \mathrm{z} 353.2>210.1$ (Cone 50, Collision 20) and $\mathrm{m} / z$ 353.2 $>222.0$ (Cone 50, Collision 20). Transition $\mathrm{m} / z 353.2>144.0$ was used for quantification of these two compounds. Transitions $m / z 195.2>110.1$ (cone 36, Collision 22) and $m / z$ 195.2 > 138.2 (cone 36, Collision 18) were used for caffeine; transitions $\mathrm{m} / z$ 351.3 $>144.1$ (cone 28, Collision 24) and $\mathrm{m} / z 351.3>170.2$ (cone 28, Collision 22) were used for deglycosylated strictosidine; transitions $\mathrm{m} / z$ 531.3 $>144.1$ (cone 32, Collision 36) and $\mathrm{m} / \mathrm{z} 351.3>352.2$ (cone 32, Collision 24) were used for detection of strictosidine. Transitions $\mathrm{m} / \mathrm{z} 355.3>117.1$ (Cone 48, Collision 42 ), $\mathrm{m} / \mathrm{z} 355.3>$ 144.1 (Cone 48, Collision 26), $\mathrm{m} / \mathrm{z} 355.3>212.2$ (Cone 48, Collision 18) and $\mathrm{m} / \mathrm{z}$ $355.3>224.2$ (Cone 48, Collision 18) were used for detection of isositsirikine, yohimbine. Transitions $\mathrm{m} / \mathrm{z} 323.2>182.0$ (Cone 50, Collision 36), $\mathrm{m} / \mathrm{z} 323.2>$ 234.1 (Cone 50, Collision 34), $\mathrm{m} / z$ 323.2 > 291.3 (Cone 50, Collision 22) were used for detection of akuammicine. Peak areas were calculated using the Waters MassLynx software and normalized.

The apparent rate under saturating substrate concentrations (observed $k_{\text {cat }}$ ) for GS1 was measured using NADPH absorbance using strictosidine $(100 \mu \mathrm{M})$, NADPH $(100 \mu \mathrm{M})$ and GS1 $(0.83 \mu \mathrm{M})$ in an assay previously reported ${ }^{17}$. The apparent $\mathrm{k}_{\text {cat }}$ was $0.04 \pm 0.007 \mathrm{~s}^{-1}$. Initial rates for GO can be calculated from the data presented in Fig. 3a: $9.73 \mathrm{nmoll}^{-1} \mathrm{~s}^{-1}(100 \mathrm{\mu M}$ concentration of strictosidine, $5 \mu \mathrm{M}$ GS1, $5 \mathrm{mM}$ NADPH) and $7.99 \mathrm{nmol}^{-1} \mathrm{~s}^{-1}$ (300 $\mu \mathrm{M}$ strictosidine, $5 \mu \mathrm{M} \mathrm{GS1}$, $5 \mathrm{mM}$ NADPH). The specific activity for GO was not calculated since it was used as a crude microsomal preparation (as is standard for microsomal cytochrome P450s).

Chiral column liquid chromatography. Synthetic akuammicine and enzymatically produced akuammicine were subjected to chiral resolution analysis by LCMS. Chromatography was performed on a Lux i-Cellulose $5(150 \times 3.0 \mathrm{~mm}, 3 \mu \mathrm{m})$ column (Phenomenex) under isocratic conditions using 60\% $10 \mathrm{mM}$ ammonium acetate and $40 \%$ acetonitrile for $10 \mathrm{~min}$ with a flow rate of $0.6 \mathrm{ml} / \mathrm{min}$. Synthetic akuammicine $(1 \mu \mathrm{l}$ of $125 \mathrm{ng} / \mathrm{ml}$ solution) and $1 \mu \mathrm{l}$ of enzyme assay were injected. Mass spectrometry detection was performed on a Waters Xevo TQ-S mass spectrometer using the transitions $\mathrm{m} / \mathrm{z} 323.2>182.0, \mathrm{~m} / \mathrm{z} 323.2>234.1, \mathrm{~m} / \mathrm{z} 323.2>$ 291.3 for detection of akuammicine.

Formaldehyde release detection assay. Release of formaldehyde as result of rearrangement catalyzed by GO (CYP71D1V1) was monitored using a fluorescence-based Nash assay as previously reported ${ }^{33}$. Nash reagent was prepared by adding $0.3 \mathrm{ml}$ of acetic acid and $0.2 \mathrm{ml}$ of acetylacetone to $100 \mathrm{ml}$ of $2 \mathrm{M}$ ammonium acetate. Enzyme assays were performed in a total volume of $200 \mu \mathrm{l}$, using $300 \mu \mathrm{M}$ strictosidine aglycone substrate, $5 \mu \mathrm{M}$ GS1, $5 \mathrm{mM} \mathrm{NADPH}$ and various quantities of GO (CYP71D1V1) microsomes ranging from 5 to $100 \mu \mathrm{l}$ in $50 \mathrm{mM}$ phosphate buffer ( $\mathrm{pH}$ 7.0). After $20 \mathrm{~min}$, enzyme assays were centrifuged for $5 \mathrm{~min}$ at $3130 \times \mathrm{g}$ for $5 \mathrm{~min}, 100 \mu \mathrm{l}$ of enzyme assay were quenched with two volumes of Nash reagent and incubated at $60{ }^{\circ} \mathrm{C}$ for $10 \mathrm{~min}$ to convert formaldehyde to diacetyldihydrolutidine, which was detected by fluorescence using a BMG Labtech CLARIOstar microplate reader at $\lambda_{\mathrm{ex}}=412 \mathrm{~nm}$ and $\lambda_{\mathrm{em}}=505 \mathrm{~nm}$. A calibration curve using formaldehyde (Sigma-Aldrich) from 0-50 $\mu \mathrm{M}$ was made for quantification. Peak areas were calculated using the BMG Labtech CLARIOstar software and normalized. Aliquots of the reaction mixtures $(10 \mu \mathrm{l})$ after centrifugation were quenched by the addition of $10 \mu \mathrm{l}$ of $100 \% \mathrm{MeOH}$. Samples were diluted further $1: 5$ in mobile phase $\left(\mathrm{H}_{2} \mathrm{O}+0.1 \%\right.$ formic acid) and centrifuged for $10 \mathrm{~min}$ at $4000 \times \mathrm{g}$ before UPLC-MS injection $(1 \mu \mathrm{l})$ and the activity of enzymes was measured by UPLC-MS as described above. Peak areas were calculated using the Waters MassLynx software and normalized.
Large-scale enzyme assay. For full characterization of GS1 and GO (CYP71D1V1) products, two large-scale enzyme assays were performed. For the characterization of the compounds (16R)-E-isositsirikine (1) and (16R)-Z-isositsirikine (2) produced by GS1, $9.2 \mathrm{mg}$ of strictosidine prepared as described previously ${ }^{17}$ were dissolved in $50 \mathrm{~mL}$ of $50 \mathrm{mM}$ phosphate buffer $(\mathrm{pH}=7.0)$. To generate strictosidine aglycone as substrate, $5 \mathrm{nM}$ of SGD enzyme was added and incubated at $37^{\circ} \mathrm{C}$ for $20 \mathrm{~min}$. The consumption of strictosidine was monitored by flow injection MS performed on an Advion express-ion Compact Mass Spectrometer. NADPH $(25 \mathrm{mg})$ and aliquots of GS1 to final concentration $5 \mu \mathrm{M}$ were added to the reaction mixture. A NADPH-generation/regeneration system consisting of glucose, glucose dehydrogenase (Sigma-Aldrich) was used additionally. The reaction was monitored by flow injection MS at $m / z 355.3$ and after $3 \mathrm{~h}$ was stopped by addition of $10 \mathrm{~mL} \mathrm{MeOH}$. The reaction mixture was centrifuged for 10 $\mathrm{min}$ at $3,130 \mathrm{~g}$. The supernatant was loaded onto an SPE cartridge (RP18; $10 \mathrm{~g} ; 60$ $\mathrm{ml}$ ), the SPE cartridge washed with 2 volumes of water and the enzyme reaction product was eluted with 1 volume of $\mathrm{MeOH}$. The methanol SPE fraction was concentrated to $4 \mathrm{ml}$, filtered and products of GS1 were purified by preparative HPLC (details of the method are below).

For the characterization of compound 3 (akuammicine) produced by GS1 and GO (CYP71D1V1), $8.4 \mathrm{mg}$ of strictosidine were dissolved in $50 \mathrm{ml}$ of $50 \mathrm{mM}$ phosphate buffer $(\mathrm{pH}=7.0)$. To generate strictosidine aglycone as substrate, $5 \mathrm{nM}$ of SGD enzyme were added and incubated at $37^{\circ} \mathrm{C}$ for $20 \mathrm{~min}$. The consumption of strictosidine was monitored by flow injection MS performed on an Advion express-ion Compact Mass Spectrometer. NADPH $(25 \mathrm{mg})$, aliquots of GS1 to final concentration $5 \mu \mathrm{M}$ and $12.5 \mathrm{ml}$ of microsomal protein containing GO (CYP71D1V1) were added to reaction mixture. A NADPH-generation/ regeneration system consisting of glucose, glucose dehydrogenase (Sigma-Aldrich) was also used. The reaction was monitored by flow injection MS at $\mathrm{m} / z 323.2$ and after $3 \mathrm{~h}$ was stopped by addition of $10 \mathrm{ml} \mathrm{MeOH}$. The reaction mixture was centrifuged for $10 \mathrm{~min}$ at $3130 \times \mathrm{g}$. The supernatant was loaded onto an SPE cartridge (RP18; $10 \times g ; 60 \mathrm{ml})$, the SPE cartridge was washed with 2 volumes of water and enzyme reaction product was eluted with 1 volume of $\mathrm{MeOH}$. The methanol SPE fraction was concentrated to $4 \mathrm{ml}$, filtered and products of enzymatic reaction were purified by preparative HPLC.

Preparative HPLC was performed on a Thermo Dionex Ultimate 3000 chromatography apparatus (Ultimate 3000 Pump, Ultimate 3000 Various Wavelength Detector) using a Waters XBridge BEH C18 $5 \mu 10 \times 250$ OBD.). The solvents used ammonium hydroxide $\left(\mathrm{NH}_{4} \mathrm{OH}\right)$ as Solvent $\mathrm{A} 3$ and $100 \%$ acetonitrile as Solvent B3, with a flow rate of $5.0 \mathrm{ml} / \mathrm{min}$. Injection volume was 500 $\mu \mathrm{l}$. For the isolation the gradient profile was $0 \mathrm{~min}, 30 \% \mathrm{~B}$; from 0 to $15 \mathrm{~min}$, linear gradient to $95 \% \mathrm{~B} 3$; wash at $95 \% \mathrm{~B} 3$ for $2.5 \mathrm{~min}$; from $17.5 \mathrm{~min}$ to $18 \mathrm{~min}$, back to $30 \% \mathrm{~B} 3$ for $6 \mathrm{~min}$ to re-equilibrate the column. Elution of (16 R)-E-isositsirikine (1) and (16 R)-Z-isositsirikine (2) was monitored at $225 \mathrm{~nm}$, while elution of akuammicine (3) was monitored at $328 \mathrm{~nm}$. (16 R)-E-isositsirikine (1) was collected at $7.3 \mathrm{~min},(16 \mathrm{R})$-Z-isositsirikine (2) at $8.6 \mathrm{~min}$ and akuammicine (3) at $9.7 \mathrm{~min}$. The collected fractions were analyzed on a Shimadzu LCMS-IT-TOF Mass Spectrometer. The chromatographic separation was carried out on a Phenomenex Kinetex column $2.6 \mathrm{u}$ XB-C18 $100 \AA(100 \times 2.10 \mathrm{~mm}, 2.6 \mu \mathrm{m})$, and the binary solvent system consisted of Solvent $\mathrm{A} 4, \mathrm{H}_{2} \mathrm{O}+0.1 \%$ formic acid, and Solvent $\mathrm{B} 4$ acetonitrile, at a constant flow rate $600 \mu \mathrm{l} / \mathrm{min}$. The LC gradient began with $10 \%$ Solvent B4 and linearly increased to $30 \%$ Solvent B4 in $5 \mathrm{~min}$, then increased to $90 \%$ B3 in 1 min, held for 1.5 min and brought back to $10 \%$ Solvent B4. The fractions containing the compound of interest were combined, dried and used further for compound characterization. In total, $2.3 \mathrm{mg}$ of $(16 R)$-E-isositsirikine $(\mathbf{1})^{24}, \approx 400 \mu \mathrm{g}$ of $(16 R)$-Z-isositsirikine $(2)^{24}$ and $\approx 600 \mu \mathrm{g}$ of akuammicine $(3)^{26}$ were isolated.

Compound characterization. High-resolution electrospray ionization mass spectrometry spectra and UV-Vis spectra were measured with a Shimadzu IT-TOF mass spectrometer as described above. NMR spectra $\left({ }^{1} \mathrm{H}\right.$ NMR, ${ }^{13} \mathrm{C}$ NMR) were acquired using a Bruker Avance III 400 NMR spectrometer equipped with a BBFO plus $5 \mathrm{~mm}$ probe, operating at $400 \mathrm{MHz}$ for ${ }^{1} \mathrm{H}$ and $100 \mathrm{MHz}$ for ${ }^{13} \mathrm{C}$. The residual ${ }^{1} \mathrm{H}$ - and ${ }^{13} \mathrm{C}$ NMR signals of $\mathrm{CD}_{3} \mathrm{Cl}\left(\delta 7.26\right.$ for ${ }^{1} \mathrm{H}$ and $\delta 77.36$ for $\left.{ }^{13} \mathrm{C}\right)$ were used as internal chemical shift references. The number of scans depended on the concentration of the sample. The ${ }^{1} \mathrm{H}$ NMR spectra were compared with those of standards and literature data ${ }^{24,26}$. For NMR, mass spectrometry and spectroscopic data, see Supplementary Figs 5-23.

(16R)-E-isositsirikine (1). ${ }^{1} \mathrm{H}-\mathrm{NMR}\left(400 \mathrm{MHz}, \mathrm{CDCl}_{3}\right)$ : $\delta 8.66$ p.p.m. (s, br, 1 H),), $7.48(\mathrm{~d}, \mathrm{br}, J=7.6 \mathrm{~Hz}, 1 \mathrm{H}), 7.38(\mathrm{~d}, \mathrm{br}, J=7.9 \mathrm{~Hz}, 1 \mathrm{H}), 7.16(\mathrm{ddd}, J=7.9 \mathrm{~Hz}$, $J=7.2 \mathrm{~Hz}, J=1.1 \mathrm{~Hz}, 1 \mathrm{H}), 7.10(\mathrm{ddd}, J=7.6 \mathrm{~Hz}, J=7.2 \mathrm{~Hz}, J=1.1 \mathrm{~Hz}, 1 \mathrm{H}), 5.63$ $(\mathrm{q}, J=6.8 \mathrm{~Hz}, 1 \mathrm{H}), 4.32(\mathrm{~m}, \mathrm{br}, 1 \mathrm{H}), 3.82(\mathrm{~s}, 3 \mathrm{H}), 3.57(\mathrm{dd} J=11.3 \mathrm{~Hz}, J=5.8 \mathrm{~Hz}$ $1 \mathrm{H}), 3.54(\mathrm{~d} J=12.3 \mathrm{~Hz}, 1 \mathrm{H}), 3.51(\mathrm{dd} J=11.3 \mathrm{~Hz}, J=4.7 \mathrm{~Hz}, 1 \mathrm{H}), 3.28$ (ddd, $J=$ $13.0 \mathrm{~Hz}, J=5.7 \mathrm{~Hz}, J=0.9 \mathrm{~Hz}, 1 \mathrm{H}), 3.19-3.09(\mathrm{~m}, 2 \mathrm{H}), 3.05-2.96(\mathrm{~m}, 1 \mathrm{H}), 2.94$ $(\mathrm{d}, J=12.2 \mathrm{~Hz}, 1 \mathrm{H}), 2.65$ (ddd, $J=14.5 \mathrm{~Hz}, J=4.5 \mathrm{~Hz}, J=1.0 \mathrm{~Hz}, 1 \mathrm{H}), 2.51$ (ddd, $J=11.4 \mathrm{~Hz}, J=7.8 \mathrm{~Hz}, J=5.0 \mathrm{~Hz}, 1 \mathrm{H}), 2.29-2.15(\mathrm{~m}, 2 \mathrm{H}), 1.68(\mathrm{dd}, J=6.9$ $\mathrm{Hz}, J=1.7 \mathrm{~Hz} 3 \mathrm{H}) ;{ }^{13} \mathrm{C}-\mathrm{NMR}\left(125 \mathrm{MHz}, \mathrm{CDCl}_{3}\right): \delta 175.6,136.3,134.1,133.7$, $127.8,123.6,121.7,119.7,118.1,111.4,108.0,62.3,52.9,52.5,52.4,51.6,49.7,32.7$, 30.5, 17.8, 13.5; UV/vis: $\lambda_{\max } 225,280 \mathrm{~nm}$; HRMS $(\mathrm{m} / \mathrm{z}):[\mathrm{M}+\mathrm{H}]^{+}$calcd for $\mathrm{C}_{21} \mathrm{H}_{27} \mathrm{~N}_{2} \mathrm{O}_{3}, 355.2016$; found, 355.2020; analysis. 
(16R)-Z-isositsirikine (2). ${ }^{1} \mathrm{H}-\mathrm{NMR}\left(400 \mathrm{MHz}, \mathrm{CDCl}_{3}\right): \delta 7.88$ p.p.m. (s, br, $\left.1 \mathrm{H}\right)$, $7.46(\mathrm{~d}, \mathrm{br}, J=7.6 \mathrm{~Hz}, 1 \mathrm{H}), 7.32(\mathrm{~d}, \mathrm{br}, J=7.9 \mathrm{~Hz}, 1 \mathrm{H}), 7.14$ (ddd, $J=7.9 \mathrm{~Hz}$, $J=7.2 \mathrm{~Hz}, J=1.1 \mathrm{~Hz}, 1 \mathrm{H}$ ), 7.08 (ddd, $J=7.6 \mathrm{~Hz}, J=7.2 \mathrm{~Hz}, J=1.1 \mathrm{~Hz}, 1 \mathrm{H}), 5.46$ $(\mathrm{q}, J=6.8 \mathrm{~Hz}, 1 \mathrm{H}), 3.91(\mathrm{dd} J=11.3 \mathrm{~Hz}, J=7.8 \mathrm{~Hz}, 1 \mathrm{H}), 3.81(\mathrm{dd} J=11.3 \mathrm{~Hz}$ $J=4.5 \mathrm{~Hz}, 1 \mathrm{H}), 3.78(\mathrm{~d} J=12.7 \mathrm{~Hz}, 1 \mathrm{H}), 3.74(\mathrm{~s}, 3 \mathrm{H}), 3.63(\mathrm{~d}, \mathrm{br}, J=10.5 \mathrm{~Hz}$ $1 \mathrm{H}), 3.17$ (ddd, $J=10.8 \mathrm{~Hz}, J=5.5 \mathrm{~Hz}, J=1.0 \mathrm{~Hz}, 1 \mathrm{H}), 3.05-2.93(\mathrm{~m}, 2 \mathrm{H}), 2.90$ $(\mathrm{d}, J=12.7 \mathrm{~Hz}, 1 \mathrm{H}), 2.78-2.67(\mathrm{~m}, 2 \mathrm{H}), 2.67-2.58(\mathrm{~m}, 1 \mathrm{H}), 2.15(\mathrm{ddd}, J=12.5 \mathrm{~Hz}$, $J=4.5 \mathrm{~Hz}, J=4.0 \mathrm{~Hz}, 1 \mathrm{H}), 1.72(\mathrm{~d}, J=6.8 \mathrm{~Hz}, 3 \mathrm{H}), 1.70-1.65(\mathrm{~m}, 1 \mathrm{H}) ;{ }^{13} \mathrm{C}-\mathrm{NMR}$ $\left(125 \mathrm{MHz}, \mathrm{CDCl}_{3}\right.$ ) (extracted from ${ }^{1} \mathrm{H}-{ }^{13} \mathrm{C}$ HSQC): $\delta 121.7,119.7,119.1,118.3$, $111.2,62.7,58.7,54.7,52.6,52.0,49.2,41.1,34.5,21.2,13.5$ UV/vis: $\lambda_{\max } 225,279$ $\mathrm{nm}$; HRMS $(\mathrm{m} / z)$ : $[\mathrm{M}+\mathrm{H}]^{+}$calcd for $\mathrm{C}_{21} \mathrm{H}_{27} \mathrm{~N}_{2} \mathrm{O}_{3}, 355.2016$; found, 355.2014; analysis.

Akuammicine (3). ${ }^{1} \mathrm{H}-\mathrm{NMR}\left(600 \mathrm{MHz}, \mathrm{CDCl}_{3}\right): \delta 9.00$ p.p.m. (s, br, $\left.1 \mathrm{H}\right), 7.24$ (d, br, $J=7.6 \mathrm{~Hz}, 1 \mathrm{H}), 7.15$ (ddd, $J=7.6 \mathrm{~Hz}, J=7.6 \mathrm{~Hz}, J=1.0 \mathrm{~Hz}, 1 \mathrm{H}$ ), 6.89 (ddd, $J=7.6 \mathrm{~Hz}, J=7.6 \mathrm{~Hz}, J=1.0 \mathrm{~Hz}, 1 \mathrm{H}), 6.82(\mathrm{~d}, \mathrm{br}, J=7.6 \mathrm{~Hz}, 1 \mathrm{H}), 5.35$ $(\mathrm{q}, \mathrm{br}, J=6.2 \mathrm{~Hz}, 1 \mathrm{H}), 4.03(\mathrm{~m}, \mathrm{br}, 1 \mathrm{H}), 3.94(\mathrm{~m}, \mathrm{br}, 1 \mathrm{H}), 3.89(\mathrm{~d}, \mathrm{br}, J=14.9 \mathrm{~Hz}$, $1 \mathrm{H}), 3.28(\mathrm{~m}, 1 \mathrm{H}), 3.02(\mathrm{dd}, J=12.4 \mathrm{~Hz}, J=6.7 \mathrm{~Hz}, 1 \mathrm{H}), 2.95(\mathrm{~d}, J=15.0 \mathrm{~Hz}$, $1 \mathrm{H}), 2.51(\mathrm{ddd}, J=12.6 \mathrm{~Hz}, J=12.6 \mathrm{~Hz}, J=6.8 \mathrm{~Hz}, 1 \mathrm{H}), 2.42(\mathrm{ddd}, J=13.8 \mathrm{~Hz}$, $J=4.0 \mathrm{~Hz}, J=2.3 \mathrm{~Hz}, 1 \mathrm{H}), 1.82(\mathrm{dd}, J=12.3 \mathrm{~Hz}, J=5.5 \mathrm{~Hz}, 1 \mathrm{H}), 1.60$ $(\mathrm{d}, J=6.9 \mathrm{~Hz}, 3 \mathrm{H}), 1.30$ (ddd $J=13.8 \mathrm{~Hz}, J=2.8 \mathrm{~Hz}, J=2.8 \mathrm{~Hz}, 1 \mathrm{H}) ;{ }^{13} \mathrm{C}-\mathrm{NMR}$ $\left(150 \mathrm{MHz}, \mathrm{CDCl}_{3}\right)$ (extracted from ${ }^{1} \mathrm{H}-{ }^{13} \mathrm{C}$ HSQC \& ${ }^{1} \mathrm{H}-{ }^{13} \mathrm{C}$ HMBC): $\delta 167.8$, $143.1,139.3,136.2,127.8,121.1,120.9,120.3,109.5,61.7,57.4,56.9,56.2,51.0,46.1$, 30.8, 29.7, 12.9. UV/vis: $\lambda_{\max } 204,225,293,328 \mathrm{~nm}$; HRMS $(\mathrm{m} / \mathrm{z}):[\mathrm{M}+\mathrm{H}]^{+}$calcd for $\mathrm{C}_{20} \mathrm{H}_{23} \mathrm{~N}_{2} \mathrm{O}_{2}$, 323.1754; found, 323.1760; analysis.

\section{Virus-induced gene silencing. The GS1 silencing fragment was amplified} with primers 5'-GGCGCGAUGTGTTTGCAATTTCGATATGG-3' and $5^{\prime}$-GGTTGCGAUATAGGATCGTTCCCCTTG-3', to give a gene fragment of 266 bp. However, the very high nucleotide sequence identity (95\%) of GS2 to GS1 means that co-silencing of these two genes is unavoidable. The resulting fragment, when subjected to a tnBLAST search against the C. roseus transcriptome at http:// medicinalplantgenomics.msu.edu, did not show consecutive 22 bp duplication (minimal bp sequence needed for successful silencing) to any other gene, suggesting that cross-silencing with any other gene is highly unlikely. This fragment was cloned into the pTRV2u vector as described ${ }^{17}$ and was used to silence the GS in C. roseus seedlings. Leaves from the first two pairs to emerge following inoculation were harvested from eight plants transformed with the empty pTRV2u and pTRV2u-GS1. Similarly, the GO (CYP71D1V1) silencing fragment was amplified using primers 5'-CTGAGAGGATCCTACAGTATGGCCCGA-3' and 3'-CTGAGAGGATCCATCGTTAACAAGATGAGGAACCAAT-5', to generate a $298 \mathrm{bp}$ cDNA displaying low identity with other $C$. roseus transcripts to avoid potential gene cross-silencing. After cloning this gene fragment into pTRV2u to generate pTRV2u-71D1V1, gene silencing was achieved on C. roseus plantlets through the biolistic-mediated inoculation of viral vectors ${ }^{34,35}$. Leaves from the first pair to develop post-transformation were harvested from eight plants transformed with the empty pTRV2u or pTRV2u-71D1V1. For both types of transformation, the collected leaves were frozen in liquid nitrogen, powdered using a pre-chilled mortar and pestle (leaves from GS1- silenced plants) or using a mixer mill (Retsch MM400 for leaves from GO (CYP71D1V1) silenced plants), and subjected to LCMS and qRT-PCR analysis. Each pair of plant leaves was analyzed separately, for a total of 8 biological replicates.

To assess the results of VIGS, the alkaloid content of silenced leaves was determined by LCMS. To comprehensively assess the global effect of silencing on C. roseus metabolism using the GS1 fragment, an untargeted metabolomics analysis by LCMS was performed. Leaves were weighed $(8-30 \mathrm{mg})$ and collected into a fixed volume of methanol $(200 \mu \mathrm{l})$ and incubated at $56^{\circ} \mathrm{C}$ for $60 \mathrm{~min}$. After a $30 \mathrm{~min}$ centrifugation step at $5,000 \mathrm{~g}$, an aliquot of the supernatant $(20 \mu \mathrm{l})$ was diluted to $400 \mu \mathrm{l}$ with water and analyzed on a Shimadzu LCMS-IT-TOF Mass Spectrometer. The chromatographic separation was carried out on a Phenomenex Kinetex column $2.6 \mu \mathrm{XB}-\mathrm{C} 18100 \AA(100 \times 2.10 \mathrm{~mm}, 2.6 \mu \mathrm{m})$, and the binary solvent system consisted of Solvent $\mathrm{A} 5, \mathrm{H}_{2} \mathrm{O}+0.1 \%$ formic acid, and Solvent B5, acetonitrile, at a constant flow rate $600 \mu \mathrm{l} / \mathrm{min}$. The LC gradient began with $10 \%$ Solvent B5 and linearly increased to $30 \%$ Solvent B5 in 5 min, then increased to $90 \%$ B5 in 1 min, held for 1.5 min and brought back to $10 \%$ Solvent B5. Peak areas were calculated using the Shimadzu Profiling Solution software and normalized by leaf mass (fresh weight). Analysis revealed that the only significant metabolic change with the GS1 silencing fragment was the accumulation of heteroyohimbines. The diastereomers tetrahydroalstonine and ajmalicine, which are both naturally present in C. roseus seedlings, do not separate under these chromatographic conditions.

For targeted metabolomic analysis, the secondary metabolite content of GS silenced leaves was determined by a different chromatographic method. Leaf powder was weighed $(1-6 \mathrm{mg})$, extracted with methanol $(2 \mathrm{ml})$ and vortexed for $1 \mathrm{~min}$. After a 10 -min centrifugation step at $17,000 \mathrm{~g}$, an aliquot of the supernatant (200 $\mu \mathrm{l}$ ) was filtered through $0.2 \mu \mathrm{m}$ PTFE filters and analyzed on a Waters Xevo TQ-MS. The chromatographic separation was carried out with an Acquity BEH C18 $1.7 \mu \mathrm{m} 2.1 \times 50 \mathrm{~mm}$ column and the binary solvent system consisted of solvent A6, which was $0.1 \% \mathrm{NH}_{4} \mathrm{OH}$ and solvent $\mathrm{B} 6$, which was $0.1 \% \mathrm{NH}_{4} \mathrm{OH}$. A linear gradient from $0 \%$ to $65 \%$ B6 in $17.5 \mathrm{~min}$ was applied for separation of the compounds followed by an increase to $100 \%$ B6 at $18 \mathrm{~min}$, a 2 min wash step and a re-equilibration at $0 \% \mathrm{~B} 6$ for $3 \mathrm{~min}$ before the next injection. The column was kept at $60^{\circ} \mathrm{C}$ throughout the analysis and the flow rate was $0.6 \mathrm{ml} / \mathrm{min}$. MS detection was performed in positive mode ESI. Capillary voltage was $3.0 \mathrm{kV}$; the source was kept at $150{ }^{\circ} \mathrm{C}$; desolvation temperature was $500^{\circ} \mathrm{C}$; cone gas flow, $50 \mathrm{l} / \mathrm{h}$ and desolvation gas flow, $800 \mathrm{l} / \mathrm{h}$. Unit resolution was applied to each quadrupole. Multiple Reactions Monitoring (MRM) signals were used for detection and quantification of caffeine, heteroyohimbine alkaloids, strictosidine, akuammicine as reported above.

For targeted metabolic analyses of the alkaloid content of the GO (CYP71D1V1)-silenced plants, alkaloids were extracted from lyophilized leaves by grinding tissues with a mixer mill (Restch, MM 400) during $3 \mathrm{~min}$ at the maximal frequency. The resulting powders were incubated in $1 \mathrm{ml}$ methanol (containing $0.1 \%$ formic acid) under vigorous shaking during $1 \mathrm{~h}$ at $24^{\circ} \mathrm{C}$. After centrifugation $(15,000 \times g, 15 \mathrm{~min})$, supernatants were collected and used for quantification. Alkaloid quantifications were performed using an UPLC-MS chromatography system coupled to a SQD mass spectrometer equipped with an electrospray ionization (ESI) source controlled by Masslynx 4.1 software (Waters, Milford, MA). Analyte separation was performed on a Waters Acquity HSS T3 C18 column $(150 \times 2.1 \mathrm{~mm}$, i.d. $1.8 \mu \mathrm{m})$ with a flow rate of $0.4 \mathrm{ml} / \mathrm{min}$ at $55^{\circ} \mathrm{C}$ and the volume of injection was $5 \mu \mathrm{L}$. The following linear elution gradient was used: acetonitrilewater-formic acid from 10:90:0.1 to 60:40:0.1 over $18 \mathrm{~min}$. The capillary and sample cone voltages were $3,000 \mathrm{~V}$ and $30 \mathrm{~V}$, respectively. The cone and desolvation gas flow rates were 60 and $800 \mathrm{l} / \mathrm{h}$. MS experiments were carried out in positive mode in the selected ion-monitoring mode using $\mathrm{m} / \mathrm{z} 337$ for catharanthine $\left([\mathrm{M}+\mathrm{H}]^{+}, \mathrm{RT}=12.33 \mathrm{~min}\right), \mathrm{m} / z 457$ for vindoline $\left([\mathrm{M}+\mathrm{H}]^{+}\right.$, $\mathrm{RT}=14.69 \mathrm{~min}), \mathrm{m} / z 427$ for vindorosine $\left([\mathrm{M}+\mathrm{H}]^{+}, \mathrm{RT}=15.03 \mathrm{~min}\right), \mathrm{m} / z 353$ for ajmalicine $\left([\mathrm{M}+\mathrm{H}]^{+}, \mathrm{RT}=11.7 \mathrm{~min}\right), \mathrm{m} / z 349$ for serpentine $\left([\mathrm{M}+\mathrm{H}]^{+}\right.$, $\mathrm{RT}=13.01 \mathrm{~min})$ and $\mathrm{m} / z 375$ for loganic acid $\left([\mathrm{M}-\mathrm{H}]^{-}, \mathrm{RT}=4.94 \mathrm{~min}\right)$. The acquired data was processed by the QuanLynx $x^{\mathrm{mu}}$ software (Waters, UK). Relative quantification was performed by correcting peak areas by sample masses.

Gene silencing was confirmed by qRT-PCR. For GS1-silenced plants, RNA extraction was performed using the RNeasy Plant Mini Kit (Qiagen). RNA ( $1 \mu \mathrm{g})$ was used to synthesize cDNA in $20 \mu \mathrm{l}$ reactions using the iScript cDNA Synthesis Kit (Bio-Rad). The cDNA served as template for quantitative PCR performed using the CFX96 Real-Time PCR Detection System (Bio-Rad) using the SSO Advanced SYBR Green Supermix (Bio-Rad). Each reaction was performed in a total reaction volume of $20 \mu \mathrm{l}$ containing an equal amount of cDNA, $0.25 \mathrm{mM}$ forward and reverse primers, and $1 \mathrm{x}$ SsoAdvanced SYBRGreen Supermix (Bio-Rad). The reaction was initiated by a denaturation step at $95^{\circ} \mathrm{C}$ for $10 \mathrm{~min}$ followed by $41 \mathrm{cycles}$ at $95^{\circ} \mathrm{C}$ for $15 \mathrm{~s}$ and $60^{\circ} \mathrm{C}$ for $1 \mathrm{~min}$. For GO (CYP71DV1) silenced plants, RNA was extracted with the NucleoSpin RNA Plant kit (Macherey- Nagel) and $1 \mu \mathrm{g}$ from each extraction was retro-transcribed using the RevertAid first strand cDNA synthesis kit (ThermoFischer Scientific) with random hexamers $(5 \mu \mathrm{M})$ according to the manufacturer's instructions. Gene expression levels were monitored by quantitative PCR performed using the Dynamo ColorFlash probe qPCR kit (ThermoFischer Scientific) in a $15 \mu \mathrm{l}$ final volume containing $6 \mu \mathrm{l}$ diluted template cDNA and the forward and reverse primers $(0.5 \mu \mathrm{M})$. Amplifications were performed on a CFX96 real-time SYBR system (Bio-Rad) using detection of SYBR green with the following conditions: $95^{\circ} \mathrm{C}$ for $7 \mathrm{~min}, 40$ cycles at $95^{\circ} \mathrm{C}$ for $10 \mathrm{~s}$ and $60^{\circ} \mathrm{C}$ for $40 \mathrm{~s}$. Melting curves were used to determine the specificity of the amplifications. Relative quantification of gene expression was calculated according to the delta-delta cycle threshold method using the $40 \mathrm{~S}$ ribosomal protein S9 (RPS9). The primers $5^{\prime}$-TTGAGCCGTATCAGAAATGC- $3^{\prime}$ and $5^{\prime}$-CCCTCATCA AGCAGACCATA- $3^{\prime}$ were used for RPS9, and $5^{\prime}$-TACTGAAGTTATTGGGAT TGA- ${ }^{\prime}$ and $5^{\prime}$-TTCAATGTATTTCCAATGTCA- $3^{\prime}$ were used for GS1 and 5'-GCTGAGTTTATGTTGGCTGCTATGTT- ${ }^{\prime}$ and $5^{\prime}$-ATAGTTGGCAAAGA CAGACTAATCGT-3' for GO (CYP71D1V1). All primer pair efficiencies were between $98 \%$ and $108 \%$, and the individual efficiency values were considered in the calculation of normalized relative expression, which was performed using the Gene Study feature of CFX Manager Software. All biological samples were measured in technical duplicates (GS1-silenced plants) or triplicates (GO (CYP71D1V1)silenced plants).

Transcript distribution analysis. Epidermis-enriched fractions were generated according to a previously described procedure ${ }^{36}$. Briefly, a cotton swab was dipped into a carborundum powder (particle size $<300$ grit, Fischer) and used to abrade both lower and upper epidermis layers of young $C$. roseus leaves. Abraded leaves were dipped in $4 \mathrm{ml}$ of Trizol (Life Technologies) for $5 \mathrm{~s}$ in a $15 \mathrm{~mL}$ centrifuge tube A total of $3 \times 10$ leaves were abraded and RNAs were extracted according to the manufacturer's protocol. The RNA pellet resulting from the isopropanol precipitation was washed with 70\% ethanol and re-suspended in $100 \mu \mathrm{l}$ of RNAse-free water. Excess sugars were removed by precipitation with $10 \%$ ethanol for $5 \mathrm{~min}$ on ice and centrifugation for $5 \mathrm{~min}$ at $15,000 \times g$ and $4{ }^{\circ} \mathrm{C}$. The supernatant was recovered and precipitated with 0.5 volume of $3 \mathrm{M}$ sodium acetate ( $\mathrm{pH} 5.2$ ) and 2.5 volumes of $100 \%$ ethanol. The pellet was washed with $70 \%$ ethanol and re-suspended with $20 \mu \mathrm{l}$ of RNase-free water. Total RNAs from whole young leaves were also extracted with Trizol (Life Technologies) according to the manufacturer's protocol. RNA from both fractions was quantified using a NanoDrop ${ }^{\circledR}$ ND-1000 and $1 \mu \mathrm{g}$ was retro-transcribed with the RevertAid First Strand cDNA Synthesis Kit according to provider's instructions (ThermosFisher Scientific). Gene expression 
levels were measured by quantitative PCR run on a CFX96 Touch Real-Time PCR System (Bio-Rad). Each reaction was performed in a total reaction volume of $25 \mu \mathrm{l}$ containing an equal amount of cDNAs (1/3 dilution), $1 \times$ DyNAmo ColorFlash Probe qPCR Kit (Thermo Fisher Scientific), and $0.05 \mu \mathrm{M}$ forward and reverse specific primers, qSTRfor 5'-CATAGCTCTGTGGGTATATTAGTGT-3', qSTRrev 5'-CATAGCTCTGTGGGTATATTAGTGT-3'; qSGDfor 5'-CTTCGACAACTTC GAATGGAA-3'; qSGDrev 5'-CTTCTTGACTAACTCAACTAGT-3'; qHDSfor 5'- GTCCCTTACTGAACCTCCAGAG-3'; qHDSrev 5'-AATCACCTGTCCTGC GTTGG-3'; qRPS9for 5' - TTACAAGTCCCTTCGGTGGT-3', qRPS9rev 5'-TGC TTATTCTTCATCCTCTTCATC-3': qGS1for 5'-TTGACTATCTCAGCACTGCT ATGGA-3', qGS1rev 5'-GAACCAAGATGAAGACGGCACCTAA-3' and qCYP71D1V1for 5' ${ }^{\prime}$-ATGGATTTCTATGGAAGTAACTTTGAA- ${ }^{\prime}$ ' and qCYP71D1V1rev 5'-AGTCCTCAGTCAAATCAATTTCTTCT-3'. The amplification program was $95^{\circ} \mathrm{C}$ for $7 \mathrm{~min}$ (polymerase heat activation), followed by 40 cycles containing 2 steps, $95^{\circ} \mathrm{C}$ for $10 \mathrm{sec}$ and $60^{\circ} \mathrm{C}$ for $40 \mathrm{sec}$. Quantification of transcript copy number was performed with calibration curves and normalization with the RPS9 reference gene and expressed relative to the amount of transcript measured in the whole leaf fraction. All amplifications were performed in triplicate and repeated at least on two independent biological repeats. Expression of hydroxymethylbutenyl 4-diphosphate synthase (HDS) known to accumulate within internal phloem associated parenchyma was used as a control ${ }^{37}$.

Subcellular localization. Determination of the subcellular localization of GS1 and GO (CYP71D1V1) was performed by subcloning the full length GS1 and CYP71D1V1 coding sequences into the pSCA-cassette vector as YFP fusions. To avoid masking of the potential $\mathrm{N}$-terminal transmembrane helix, CYP71D1V1 was only expressed as N-terminal fusion with YFP (GO (CYP71D1V1)-YFP) while GS1 was expressed as both $\mathrm{N}$-terminal or C-terminal fusions (GS1-YFP and YFP-GS1). Amplifications were achieved with primers $5^{\prime}$-CTGAGAACTAGTATGGCCG GAGAAACAACCAAAC- $3^{\prime}$ and $5^{\prime}$-CTGAGAACTAGTTTCCTCAAATTTCAAT GTATTTCCAATG- $3^{\prime}$ for GS1; and 5'-CTGAGAACTAGTATGGAGTTTTCTT

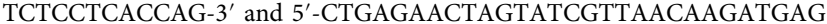
GAACCAATT-3' for CYP71D1V1. The nuclear (nucleus-CFP), nucleocytosolic (CFP) and endoplasmic reticulum (ER-CFP) markers were described previously ${ }^{17}$. Transient transformation of $C$. roseus cells by particle bombardment and fluorescence imaging were performed following the procedures previously described 35,38 . C. roseus cells were bombarded with DNA-coated gold particles $(1 \mu \mathrm{m})$ and 1,100 psi rupture disc at a stopping-screen-to-target distance of $6 \mathrm{~cm}$, using the Bio-Rad PDS1000/He system and $400 \mathrm{ng}$ of each plasmid per transformation. Cells were cultivated for $16 \mathrm{~h}$ to $38 \mathrm{~h}$ before being harvested and observed. The subcellular localization was determined using an Olympus BX-51 epifluorescence microscope equipped with an Olympus DP-71 digital camera and a combination of YFP and CFP filters.

Data availability. Sequence data for GS1 (KF302079.1), GS2 (KF302078.1). and GO (JN613015) have been deposited in GenBank as described in the manuscript. Transcriptome data used in this study has already been published as referenced in the manuscript (see also, http://medicinalplantgenomics.msu.edu/). Data supporting the findings of this study are available within the article and its supplementary information files and from the corresponding author upon reasonable request.

Received: 3 February 2017 Accepted: 6 June 2017

Published online: 22 August 2017

\section{References}

1. O'Connor, S. E. \& Maresh, J. J. Chemistry and biology of monoterpene indole alkaloid biosynthesis. Nat. Prod. Rep. 23, 532-547 (2006).

2. Courdavault, V. et al. A look inside an alkaloid multisite plant: the Catharanthus logistics. Curr. Opin. Plant Biol. 19, 43-50 (2014).

3. Geerlings, A., Ibanez, M. M., Memelink, J., van Der Heijden, R. \& Verpoorte, R. Molecular cloning and analysis of strictosidine beta-D-glucosidase, an enzyme in terpenoid indole alkaloid biosynthesis in Catharanthus roseus. J. Biol. Chem 275, 3051-3056 (2000).

4. Battersby, A. R. \& Hall, E. S. Intermediacy of Geissoschizine in indole alkaloid biosynthesis. Rearrangement to the Strychnos skeleton. J. Chem. Soc. D, 793-794 (1969).

5. Scott, A. I., Cherry, P. C. \& Qureshi, A. A. Mechanism of indole alkaloid biosynthesis. The Corynanthe-Strychnos relationship. J. Am. Chem. Soc. 91, 4932-4933 (1969).

6. Battersby, A. R. \& Gibson, K. H. Further studies on rearrangements during biosynthesis of indole alkaloids. J. Chem. Soc. D Chem. Commun. 902-904 (1971).

7. Qureshi, A. A. \& Scott, A. I. Biosynthesis of indole alkaloids: sequential precursor formation and biological conversion in Vinca rosea. Chem. Commun. 948-950 (1968).
8. Scott, A. I. \& Qureshi, A. A. Biogenesis of Strychnos, Aspidosperma, and Iboga alkaloids. Structure and reactions of preakuammicine. J. Am. Chem. Soc. 91, 5874-5876 (1969).

9. Eckermann, R. \& Gaich, T. The double-bond configuration of corynanthean alkaloids and its impact on monoterpenoid indole alkaloid biosynthesis. Chemistry 22, 5749-5755 (2016).

10. Benayad, S., Ahamada, K., Lewin, G., Evanno, L. \& Poupon, E. Preakuammicine: A Long-Awaited Missing Link in the Biosynthesis of Monoterpene Indole Alkaloids. Eur. J. Org. Chem. 2016, 1494-1499 (2016).

11. Menzies, J. R. W., Paterson, S. J., Duwiejua, M. \& Corbett, A. D. Opioid activity of alkaloids extracted from Picralima nitida (fam. Apocynaceae). Eur. J. Pharmacol. 350, 101-108 (1998).

12. Corbett, A. D., Menzies, J. R. W., MacDonald, A., Paterson, S. J. \& Duwiejua, M The opioid activity of akuammine, akuammicine and akuammidine: alkaloids extracted from Picralima nitida (fam. Apocynaceae). Br. J. Pharmacol 119, 334 (1996).

13. Gongora-Castillo, E. et al. Development of transcriptomic resources for interrogating the biosynthesis of monoterpene indole alkaloids in medicinal plant species. PLoS ONE 7, e52506 (2012).

14. Kellner, F. et al. Genome-guided investigation of plant natural product biosynthesis. Plant J. 82, 680-92 (2015).

15. Dugé de Bernonville, T. et al. Folivory elicits a strong defense reaction in Catharanthus roseus: metabolomic and transcriptomic analyses reveal distinct local and systemic responses. Sci. Rep 7, 40453 (2017).

16. Miettinen, K. et al. The seco-iridoid pathway from Catharanthus roseus. Nat. Commun. 5, 3606 (2014).

17. Stavrinides, A. et al. Structural investigation of heteroyohimbine alkaloid synthesis reveals active site elements that control stereoselectivity. Nat. Commun. 7, 12116 (2016).

18. Stavrinides, A. et al. Unlocking the diversity of alkaloids in Catharanthus roseus: nuclear localization suggests metabolic channeling in secondary metabolism. Chem. Biol. 22, 336-341 (2015).

19. Werck-Reichhart, D. \& Feyereisen, R. Cytochromes P450: a success story. Genome Biol. 1, Reviews3003 (2000).

20. Irmler, S. et al. Indole alkaloid biosynthesis in Catharanthus roseus: new enzyme activities and identification of cytochrome P450 CYP72A1 as secologanin synthase. Plant J. 24, 797-804 (2000).

21. Yamamoto, H., Katano, N., Ooi, A. \& Inoue, K. Secologanin synthase which catalyzes the oxidative cleavage of loganin into secologanin is a cytochrome P450. Phytochemistry 53, 7-12 (2000).

22. Huang, L. et al. Molecular characterization of the pentacyclic triterpenoid biosynthetic pathway in Catharanthus roseus. Planta 236, 1571-1581 (2012).

23. Scott, A. I. Biosynthesis of the indole alkaloids. Acc. Chem. Res. 3, 151-157 (1970).

24. Lousnasmaa, M., Jokela, R., Hanhinen, P., Miettinen, J. \& Salo, J. Preparation and conformational study of Z- and E-Isositsirikine epimers and model compounds. Determination of their C-16 configurations. Tetrahedron 50, 9207-9222 (1994).

25. Hirata, T., Lee, S.-L. \& Scott, A.I. Biosynthesis of $(16 R)$-isositsirikine from geissoschizine with a cell-free extract of Catharanthus roseus callus. J. Chem. Soc. Chem. Commun. 1979, 1081-1083 (1979).

26. Hong, A. Y. \& Vanderwal, C. D. A synthesis of alsmaphorazine B demonstrates the chemical feasibility of a new biogenetic hypothesis. J. Am. Chem. Soc. 137, 7306-7309 (2015).

27. Murata, J., Roepke, J., Gordon, H. \& De Luca, V. The leaf epidermome of Catharanthus roseus reveals Its biochemical specialization. Plant Cell $\mathbf{2 0}$, 524-542 (2008).

28. Heimberger, S. I. \& Scott, I. A. Biosynthesis of strychnine. J. Chem. Soc. Chem. Commun. 1973, 217-218 (1973).

29. Jones, S. B., Simmons, B., Mastracchio, A. \& MacMillan, D. W. Collective synthesis of natural products by means of organocascade catalysis. Nature $\mathbf{4 7 5}$ 183-188 (2011).

30. Duge de Bernonville, T. et al. Characterization of a second secologanin synthase isoform producing both secologanin and secoxyloganin allows enhanced de novo assembly of a Catharanthus roseus transcriptome. BMC Genomics 16, 619 (2015).

31. Patro, R., Duggal, G., Love, M.I., Irizarry, R.A. \& Kingsford, C. Salmon provides fast and bias-aware quantification of transcript expression. Nat. Methods 14, 417-419 (2017).

32. Pompon, D., Louerat, B., Bronine, A. \& Urban, P. Yeast expression of animal and plant P450s in optimized redox environments. Methods Enzymol 272, 51-64 (1996).

33. Farrow, S. C. \& Facchini, P. J. Dioxygenases catalyze O-demethylation and O, $\mathrm{O}$-demethylenation with widespread roles in benzylisoquinoline alkaloid metabolism in opium poppy. J. Biol. Chem. 288, 8997-29012 (2013).

34. Carqueijeiro, I. et al. Virus-induced gene silencing in Catharanthus roseus by biolistic inoculation of tobacco rattle virus vectors. Plant Biol. 17, 1242-1246 (2015). 
35. Foureau, E. et al. Prequels to synthetic biology: From candidate gene identification and validation to enzyme subcellular localization in plant and yeast cells. Methods Enzymol 576, 167-206 (2016).

36. Payne, R., et al. An NPF transporter exports a central monoterpene indole alkaloid intermediate from the vacuole. Nat. Plants 3, 16208 (2017).

37. Burlat, V., Oudin, A., Courtois, M., Rideau, M. \& St-Pierre, B. Co-expression of three MEP pathway genes and geraniol 10-hydroxylase in internal phloem parenchyma of Catharanthus roseus implicates multicellular translocation of intermediates during the biosynthesis of monoterpene indole alkaloids and isoprenoid-derived primary metabolites. Plant J. 38, 131-141 (2004).

38. Guirimand, G. et al. Optimization of the transient transformation of Catharanthus roseus cells by particle bombardment and its application to the subcellular localization of hydroxymethylbutenyl 4-diphosphate synthase and geraniol 10-hydroxylase. Plant Cell Rep. 28, 1215-1234 (2009).

\section{Acknowledgements}

This work was supported by grants from the European Research Council (311363), BBSRC (BB/J004561/1) (S.E.O.) and from the Région Centre-Val de Loire, France (ABISAL grant and BioPROPHARM project -ARD2020) (V.C.). J.F. gratefully acknowledges DFG postdoctoral funding (FR 3720/1-1) and T.T.-T.D. an EMBO Long trem Fellowship (ALTF 239-2015). We gratefully acknowledge the generous gift of akuammicine from Chris Vanderwal (UC Irvine).

\section{Author contributions}

E.C.T., I.C., S.E.O., and V.C. designed the experiments and wrote the manuscript. E.C.T. characterized GS/GO in vitro, performed GS silencing, and performed all product characterization. J.F. and T.-T.T.D. contributed to in vitro enzyme assays. I.C., T.D.d.B., and V.C. identified GO, performed GO silencing, and GO silencing results and contributed to GS/GO in vitro assays and performed localization. I.C., E.C.T., and V.C. identified the link between GS in vitro reactions. A.K.S. contributed to identification and characterization of GS1 and T.D.d.B., A.O., A.L., F.L., and M.C. contributed to identification and characterization of GO.

\section{Additional information}

Supplementary Information accompanies this paper at doi:10.1038/s41467-017-00154-x.

Competing interests: The authors declare no competing financial interests.

Reprints and permission information is available online at http://npg.nature.com/ reprintsandpermissions/

Publisher's note: Springer Nature remains neutral with regard to jurisdictional claims in published maps and institutional affiliations.

Open Access This article is licensed under a Creative Commons Attribution 4.0 International License, which permits use, sharing, adaptation, distribution and reproduction in any medium or format, as long as you give appropriate credit to the original author(s) and the source, provide a link to the Creative Commons license, and indicate if changes were made. The images or other third party material in this article are included in the article's Creative Commons license, unless indicated otherwise in a credit line to the material. If material is not included in the article's Creative Commons license and your intended use is not permitted by statutory regulation or exceeds the permitted use, you will need to obtain permission directly from the copyright holder. To view a copy of this license, visit http://creativecommons.org/ licenses/by/4.0/

(C) The Author(s) 2017 